\title{
Hierarchical flow of sensory information in rat somatosensory cortex
}

\author{
Houman Safaai ${ }^{1,2^{*}}$, Yanfang Zuo ${ }^{1 \dagger}$, Miguel Maravall ${ }^{3}$, Stefano Panzeri ${ }^{2}$, Mathew E Diamond ${ }^{1}$ \\ From The Twenty Third Annual Computational Neuroscience Meeting: CNS*2014 \\ Québec City, Canada. 26-31 July 2014
}

Through intracortical processing, sensory stimuli are encoded initially according to elemental features and finally by the action to be taken as a result of the stimulus. The transformation between cortical regions is still not understood although it is known that the participation of primary somatosensory cortex (S1) and secondary somatosensory cortex (S2) differs according to behavioral task [1]. To investigate the sensory information flow between $\mathrm{S} 1$ and $\mathrm{S} 2$, we recorded from both areas as rats identified textured plates through whisker palpation [2]. Neurons in S2 typically fired with a longer latency to whisker contact, consistent with sequential processing. We used linear discriminant analysis of firing rates of populations of simultaneously recorded neurons [3] in S1 and S2 to compare how they encoded the stimulus. Populations in both regions reliably encoded the stimuli, but the discriminability afforded by neuronal populations in S2 reached a peak $50 \mathrm{~ms}$ later than that of S1 populations, also consistent with sequential processing. Different rats were trained with different combinations of texture/reward associations from a set of three textures and two reward locations (left and right). This made it possible to compare the decoding of texture and the decoding of the choice of the animal (left turn versus right), both in correct and incorrect trials. S1 populations carried more information about texture while S2 populations carried more information about choice. Using linear classifiers based on the texture and turn direction classes, we compared the trial-by-trial relationship of the stimulus representation in the two regions to the animal's choice. When neuronal populations in both regions correctly encoded the stimulus, the rat made the correct

\footnotetext{
* Correspondence: houman.safaai@iit.it

+ Contributed equally

'Tactile Perception and Learning Laboratory, International School for Advanced Studies (SISSA), 34136 Trieste, Italy

Full list of author information is available at the end of the article
}

choice with $85 \%$ probability. When neuronal populations in both regions incorrectly encoded the stimulus, the rat made the correct choice with just 30\% probability. When S1 and S2 had disparate representations of the stimulus, the choice of the rat was more than twice as likely to be consistent with the output of S2 than with S1. Thus, neuronal activity in $\mathrm{S} 2$ appeared to have a more direct connection to the rat's decision. The above findings suggest a causal flow of signals from S1 to S2; to test this idea, we computed the directed information [4] between single S1 and S2 units as well as between the S1 and S2 population vectors. We found a significantly higher causality index for the texture information flow from S1 to S2 as the rat palpated the texture, while the sign and value of the causality changed during the decision period when the rat already made its decision. Finally, using a linear feedforward neural network trained with S1 or S2 inputs and outputs, and tested with $\mathrm{S} 1$ or S2 inputs and outputs, we found that the feedforward network with S1 input and S2 output had significantly higher performance with respect to the reverse directionality of the input and output. All these findings suggest a hierarchical flow of information between cortical regions, as sensation is transformed to percept and choice.

\footnotetext{
Acknowledgements

This work was supported by the SI-CODE FET-Open FP7-284533 project within the Seventh Framework for Research of the European Commission, the Human Frontier Science Program grant Neuroscience of Knowledge (RG0015/2013), the European Research Council Advanced grant CONCEPT (294498), and the European Union FET grant CORONET (269459).

Authors' details

${ }^{1}$ Tactile Perception and Learning Laboratory, International School for Advanced Studies (SISSA), 34136 Trieste, Italy. ${ }^{2}$ Center for Neuroscience and Cognitive Systems, Istituto Italiano di Tecnologia, Corso Bettini 31, 38068, Rovereto, Italy. ${ }^{3}$ Instituto de Neurociencias de Alicante, Consejo Superior de Investigaciones Científicas-Universidad Miguel Hernández, 03550 Sant Joan d'Alacant, Spain.
} 
Published: 21 July 2014

\section{References}

1. Chen JL, Carta S, Soldado-Magraner J, Schneider BL, Helmchen F: Behaviour-dependent recruitment of long-range projection neurons in somatosensory cortex. Nature 2013.

2. Zuo Y, Perkon I, Diamond ME: Whisking and whisker kinematics during a texture classification task. Philos Trans R Soc B Biol Sci 2011, 366:3058-3069.

3. Safaai $H$, von Heimendahl M, Sorando JM, Diamond ME, Maravall M: Coordinated Population Activity Underlying Texture Discrimination in Rat Barrel Cortex. J Neurosci 2013, 33:5843-5855.

4. Quinn CJ, Coleman TP, Kiyavash N, Hatsopoulos NG: Estimating the directed information to infer causal relationships in ensemble neural spike train recordings. J Comput Neurosci 2010, 30:17-44.

doi:10.1186/1471-2202-15-S1-P172

Cite this article as: Safaai et al:: Hierarchical flow of sensory information in rat somatosensory cortex. BMC Neuroscience 2014 15(Suppl 1):P172.

\section{Submit your next manuscript to BioMed Central} and take full advantage of:

- Convenient online submission

- Thorough peer review

- No space constraints or color figure charges

- Immediate publication on acceptance

- Inclusion in PubMed, CAS, Scopus and Google Scholar

- Research which is freely available for redistribution

Submit your manuscript at www.biomedcentral.com/submit 